\title{
Real-world effectiveness of abatacept for rheumatoid arthritis treatment in European and Canadian populations: a 6-month interim analysis of the 2-year, observational, prospective ACTION study
}

Hubert G Nüßlein ${ }^{1 *}$, Rieke Alten², Mauro Galeazzi ${ }^{3}$, Hanns-Martin Lorenz ${ }^{4}$, Dimitrios Boumpas ${ }^{5}$, Michael T Nurmohamed ${ }^{6}$, William G Bensen ${ }^{7}$, Gerd R Burmester ${ }^{8}$, Hans-Hartmut Peter ${ }^{9}$, Franz Rainer ${ }^{10}$, Karel Pavelka ${ }^{11}$, Melanie Chartier ${ }^{12}$, Coralie Poncet ${ }^{13}$, Christiane Rauch ${ }^{14}$ and Manuela Le Bars ${ }^{15}$

\begin{abstract}
Background: Discontinuation of rheumatoid arthritis (RA) treatment for lack or loss of initial response, tolerability issues, or development of antibodies against the therapeutic agent remains a challenge in clinical practice. Here we present a 6-month interim analysis of a 2-year prospective observational trial in Europe and Canada aiming to assess the real-world effectiveness, safety, and tolerability of intravenous abatacept for the treatment of moderate-to-severe RA.

Methods: ACTION (AbataCepT In rOutiNe clinical practice) is a prospective, observational study assessing effectiveness, safety, and tolerability of abatacept in patients with RA enrolled in Europe and Canada between May 2008 and January 2011. The patient population was divided into two groups: biologic naïve ('first-line') patients and patients who had previously failed treatment with at least one biologic agent ('second-line'). Retention rates were calculated using Kaplan-Meier curve estimates. Effectiveness was measured using European League Against Rheumatism (EULAR) response criteria, the 28-item Disease Activity Score, the Clinical Disease Activity Index (CDAI), and physical function, as assessed by the Health Assessment Questionnaire-Disability Index (HAQ-DI). Serious adverse events (SAEs) were reported for all enrolled patients.
\end{abstract}

Results: Of 1138 consecutively enrolled patients, 1114 and 1079 patients were evaluable for retention and effectiveness, respectively. Overall, retention rates were $88.6 \%$ (95\% confidence interval [CI]: 86.4, 90.4); 67.4\% of patients achieved good/moderate EULAR response; $32.8 \%$ had a CDAI Low Disease Activity State (LDAS); and 44.7\% a HAQ-DI response. Retention rates among first- and second-line patients were 93.0\% (95\% Cl: 85.9, 96.6) and 88.1\% (95\% Cl: 85.7, 90.0), respectively. The percentage of patients achieving CDAI LDAS was $40.0 \%$ (95\% Cl: $26.4,53.6)$ for first- and $32.2 \%$ (95\% Cl: 28.4, 36.0) for second-line patients and the proportion achieving a HAQ-DI response was 60.3\% (95\% Cl: 47.8, 72.9) versus $43.1 \%$ (95\% Cl: 39.0, 47.2), respectively. The incidence of SAEs was $4.7 \%$.

Conclusions: Evidence from this 6-month interim analysis suggests that abatacept offers an effective and well-tolerated treatment option for patients with RA, including those who have previously failed anti-tumor necrosis factor treatment. In addition, higher retention rates and effectiveness outcomes were observed when abatacept treatment was initiated earlier in the course of the disease.

Keywords: Rheumatoid arthritis, Biological agents, Abatacept, Effectiveness, Safety, Registries

\footnotetext{
* Correspondence: nuesslein.hu@googlemail.com

'University of Erlangen-Nuremberg, Nuremberg, Germany

Full list of author information is available at the end of the article
} 


\section{Background}

The treatment of rheumatoid arthritis (RA) in routine clinical practice comprises both biologic and non-biologic disease-modifying anti-rheumatic drugs (DMARDs), including methotrexate (MTX) and tumor necrosis factor (TNF) blocking agents. Although these treatments are beneficial for many patients, some may not respond to treatment or may lose their initial response over time [1]. Indeed, anti-TNF therapy discontinuation rates in realworld practice are about $30 \%$, based on cohort studies with median follow-up of 15-37 months [2,3]. In these studies, up to $50 \%$ of discontinuations were due to lack of efficacy and approximately $15-49 \%$ to safety issues $[2,3]$. Patients who experience lack of efficacy with one antiTNF agent often have a poorer response to a second or third anti-TNF agent, reflecting loss of efficacy and increased resistance towards TNF- $\alpha$ blockade, which, in some cases is due to the development of anti-therapeutic antibodies [2-5]. This is demonstrated in several large cohort and retrospective studies by longer retention rates for first treatment courses versus subsequent courses (hazard ratio: 2.17 ; $95 \%$ confidence interval $[\mathrm{CI}]: 1.72,2.58)$ and decreased median drug survival times for subsequent antiTNF agents (37 months for first-line agent to 13 months for third-line agent) $[3,5]$. Recent data suggest that when treatment with an anti-TNF agent shows lack of efficacy, switching to a biologic agent with a different mechanism of action may be of benefit [6].

Randomized clinical trials (RCTs) of biologics have provided information on the efficacy, safety, and tolerability of treatment options in different patient populations in a clinical research setting. However, it has been reported that treatment response rates are lower in routine clinical practice compared with RCT evidence [7], possibly because of patient selection, the use of a washout period before inclusion, differences in dosing, comorbidities, and variable adherence to therapy [7]. Because patient populations in observational studies are not subject to the strict inclusion and exclusion criteria of RCTs, observational studies often include patients with different levels of disease activity and region-specific variations in treatment. Therefore, data from real-world observational studies often supplement the findings from RCTs [8].

Abatacept is a selective T-cell costimulation modulator [9]. Evidence from RCTs has demonstrated the efficacy, safety, and tolerability of abatacept for the treatment of moderate-to-severe RA in different patient populations [10-14]. Moreover, evidence from local registries in France [15], Denmark [16], and Sweden [17], as well as evidence from a small, single-site study of abatacept in routine clinical practice [18], support the findings from RCTs. However, the observations from these small, observational cohorts need to be validated in a larger cohort of patients treated in routine clinical practice over a longer period of time. The objective of this report is to present a 6-month interim analysis of the data from the ACTION (AbataCepT In rOutiNe clinical practice) study, a 2-year prospective, observational cohort study that enrolled patients with RA in Europe and Canada to evaluate patient retention and the effectiveness of treatment with abatacept in routine clinical practice.

\section{Methods}

\section{Study design and patient population}

ACTION was a non-interventional, international, multicenter, prospective, observational cohort study to evaluate patient retention and the effectiveness of intravenous abatacept treatment in patients with RA in Europe and Canada. Patients were enrolled prospectively between May 2008 and January 2011, either on, or within 3 months of, initiating treatment with abatacept according to the Summary of Product Characteristics (SmPC) in Europe and the Product Monograph in Canada. Patients already on treatment with the study drug (169/1114 [15.2\%]) were included only if baseline data were available and could be collected retrospectively.

In all participating countries, abatacept was required to have market authorization and a reimbursement policy to ensure that eligible patients had access to the drug. No product was provided to physicians or patients by the study sponsor. This observational study did not interfere with a physician's routine clinical practice. Moreover, the decision to treat a patient with abatacept was made before their enrollment in the study. By using a process of random selection from a comprehensive list of rheumatologists, the investigators in each country were geographically balanced and representative of rheumatologists who treat patients with biologics.

Enrolled patients provided informed written consent, were over 18 years of age, of either gender, with an established diagnosis of moderate-to-severe RA as defined by the American College of Rheumatology revised criteria 1987 [19]. Any patients already enrolled in an interventional RA clinical trial were excluded. The study protocol and patient enrollment were approved by ethics committees and regulatory agencies in accordance with each country's requirements. The central ethics committee that first approved the study on 31 January 2008 was the Munich, Bavaria, Germany ethics committee. For each country, local ethics committee approvals were also obtained, as required by local regulations.

The ACTION study was conducted in accordance with the Declaration of Helsinki and was consistent with the International Conference on Harmonization Good Clinical Practice Guidelines [20] and Good Epidemiological Practice Guidelines [21].

Each patient was followed for up to 2 years or, if the patient discontinued abatacept treatment before the 2- 
year endpoint, for up to 6 months after abatacept discontinuation. Follow-up visits were approximately every 3 months. No formal assessment was performed to define reasons for prior treatment failure, other than those reported by the treating physician.

\section{Effectiveness assessments}

Clinical characteristics and effectiveness are reported for patients with data available at baseline and Month 6, assessed no later than 8 days after the first abatacept infusion. Previous studies have demonstrated that abatacept may have an impact on efficacy measures as early as 7 days from the first infusion [22]. Patients who had their clinical assessment more than 8 days after their first abatacept infusion were not included in the effectiveness analysis. Disease activity was evaluated using the 28-item Disease Activity Score (DAS28), based either on erythrocyte sedimentation rate (ESR) or C-reactive protein (CRP) [23,24] according to physician's choice, and Clinical Disease Activity Index (CDAI) [25]. Although investigators could report disease activity outcomes using the DAS28 and/or CDAI scores, in practice a majority of investigators reported only DAS28 scores; in addition, the CDAI score was calculated from core components collected for each patient. A sensitivity analysis was conducted on data from patients for whom both DAS28 and CDAI assessments were available and showed that the effectiveness outcomes at Month 6 in these patients were similar to those in the overall population. For DAS28, patients were classified as being in high $(>5.1)$, moderate $(>3.2$ and $\leq 5.1)$, or low disease activity state (LDAS; $\leq 3.2$ ), or remission $(<2.6)$ [26]. LDAS was defined as a CDAI score $\leq 10$, and remission was defined as a CDAI score $\leq 2.8$. European League Against Rheumatism (EULAR) response was defined as good/moderate or no response and was based on DAS28 (ESR) or DAS28 (CRP) [27]. Physical function was assessed using the Health Assessment Questionnaire-Disability Index (HAQ-DI) [28]. HAQ response was defined as a mean change from baseline in HAQ score of $\geq 0.3$ units [29]; a clinically meaningful change in physical function was defined as a mean change from baseline in HAQ score of $\geq 0.22$ units [29-31].

\section{Safety assessments}

Safety was evaluated in accordance with local regulations and registered with the drug manufacturer's global pharmacovigilance department. Related treatment-emergent adverse events (AEs) were assessed by the treating physician and reported to the pharmacovigilance department. The relationship between the study drug and serious AE (SAE) was judged by the treating physician. A SAE was defined as an AE that was fatal or life-threatening, required or extended patient hospitalization (except pregnancy), resulted in persistent or significant disability or incapacity, induced a congenital anomaly or birth defect, or was considered an important medical event. All deaths were reported whether they were treatment-related or not. Safety was presented for the entire enrolled population, regardless of prior or concomitant treatment.

\section{Statistical analyses}

The patient population was stratified by prior line of treatment into two subgroups: patients who were either biologic-naïve prior to initiating abatacept ('first-line'), or patients who had previously received and failed at least one biologic agent ('second-line'); this second group included patients initiating abatacept as a second- or further-line of treatment. Additional subgroup analyses of abatacept effectiveness and retention rates were performed for second-line patients stratified according to the number of prior anti-TNF agents failed ( 1 versus $\geq 2)$, the reason for discontinuing their previous biologic agent (primary/ secondary inefficacy or safety and tolerability), or treatment pattern at abatacept initiation (monotherapy or in combination with conventional DMARDs). Baseline characteristics and demographics are presented using descriptive statistics for patients who received at least one infusion of abatacept and had data related to abatacept exposure. Retention on abatacept, defined as consecutive time on treatment, was analyzed using a Kaplan-Meier product limit estimator and is presented at Month 6 with 95\% CIs. Patient discontinuation from abatacept treatment was recorded by the physician at any follow-up visit. In cases of abatacept discontinuation, exposure to abatacept was defined as the time between the date of the first abatacept infusion and the date of the last abatacept infusion, plus 30 days. Patients for whom data were not available at 6 months or who did not report abatacept discontinuation were censored at the date of the last available data. Effectiveness analyses were 'as-observed' for patients on treatment for whom data were available at each time point. These data were presented as proportions with 95\% CIs, mean values, or changes with accompanying standard deviations (SDs) or 95\% CIs.

\section{Results}

\section{Patient disposition}

Patient disposition is summarized in Figure 1. Of 1138 enrolled patients, 1114 (97.9\%) were evaluable for the descriptive analysis and retention rate calculation. Patients were enrolled from nine countries (Austria, Belgium, Canada, Czech Republic, Denmark, Germany, Greece, Italy, The Netherlands) with the largest patient numbers enrolled in Germany $(n=399)$, Italy $(n=236)$, Canada $(n=229)$, and Greece $(n=149)$. A total of $96.9 \%(n=$ 1079/1114) of patients were evaluable for the effectiveness analysis; comprising patients who had a baseline clinical assessment on the same day/day before their first abatacept 


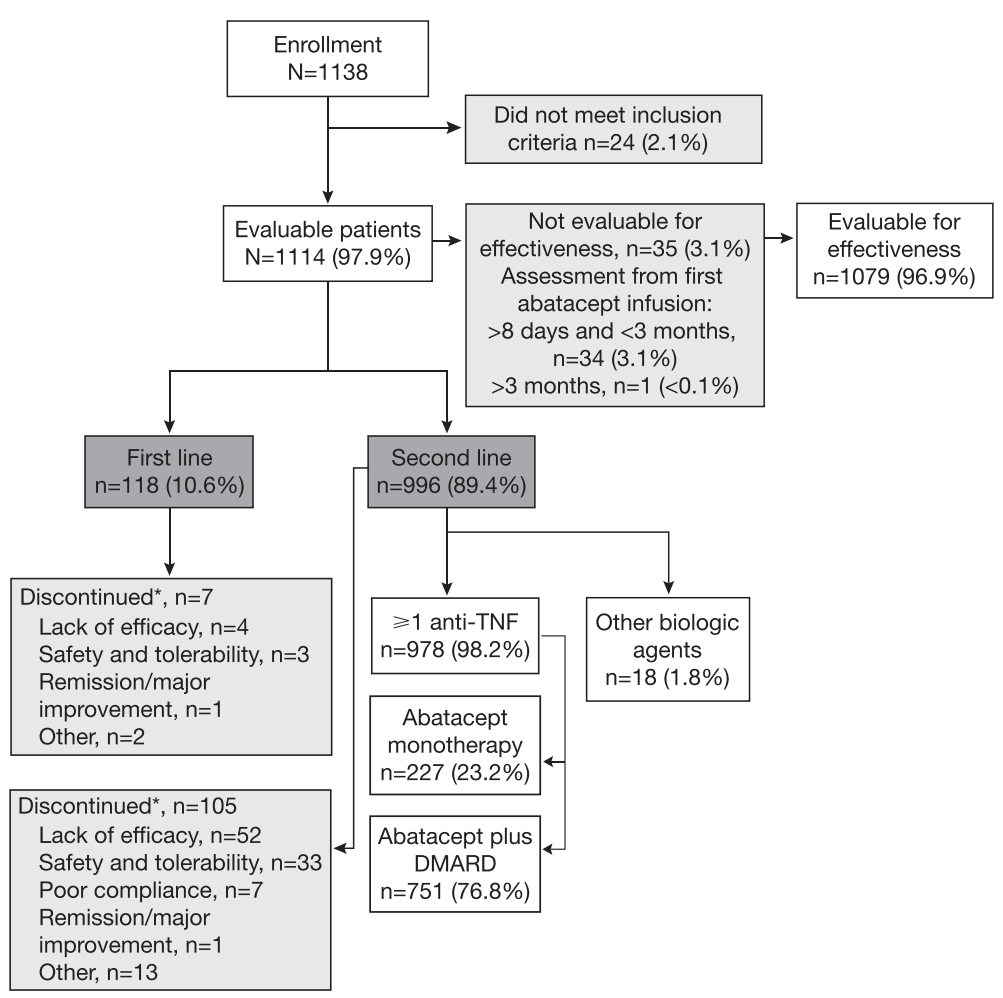

Figure 1 Patient disposition. *Patients could provide more than one reason for discontinuation. DMARD, disease-modifying anti-rheumatic drug; TNF, tumor necrosis factor.

infusion $(68.9 \%$ [ $n=767]), \geq 2$ days before their first abatacept infusion $(26.2 \%$ [ $=292]), \leq 8$ days after their first abatacept infusion $(1.4 \%[\mathrm{n}=16])$, and patients with the date of baseline clinical assessment missing $(0.4 \%[n=4])$. Of the 35 (3.1\%) patients who were not considered for the analysis of effectiveness outcomes, 34 (3.1\%) had a baseline assessment between 8 days and 3 months following their first abatacept infusion and $1(<0.1 \%)$ patient $>3$ months later. At the time of this analysis, approximately $86 \%$ of patients had outcomes at Month 6 and 14\% had either been lost to follow-up at the data cut-off or their documentation had not been received. Patient and disease characteristics at abatacept initiation (baseline) were similar in patients with and without available data at Month 6. A total of 118 (10.6\%) evaluable patients were stratified to the 'first-line' treatment group, and 996 (89.4\%) were stratified to the 'second-line' treatment group.

A total of 112 patients in the overall population discontinued treatment within the first 6 months of the study; 7 patients were in the first-line group and 105 patients were in the second-line group. Reasons for discontinuation are shown in Figure 1.

\section{Characterization of the patient population}

Baseline demographic characteristics of the evaluable patients were similar between patients in either line-of- treatment group (Table 1). Mean disease duration was shorter for patients in the first- versus second-line treatment group (6.9 versus 11.5 years (Table 1); there were more second-line treatment patients with disease duration longer than 6 years $(68.8 \%)$ compared with the first-line treatment group (38.8\%).

The mean number of non-biologic DMARDs received prior to enrolling in the study was 2.2 in the first-line group received and 2.9 in the second-line group. Prior treatment with corticosteroids or MTX was reported for high and similar proportions of first- and second-line patients (Table 1). Of the patients previously treated with biologics $(\mathrm{n}=996), 79.3 \%(\mathrm{n}=790)$ had previously failed anti-TNF treatment only, and $18.9 \%(\mathrm{n}=188)$ had treatment failures with both an anti-TNF and a nonanti-TNF biologic. Of the $823(84.1 \%)$ patients who received anti-TNF therapy before enrolling in the study, 41.2\% $(\mathrm{n}=339)$ received adalimumab, 40.2\% $(\mathrm{n}=331)$ etanercept, $17.1 \%(\mathrm{n}=141)$ infliximab, $0.9 \%(\mathrm{n}=7)$ certolizumab, and $0.6 \%(n=5)$ golimumab. Of patients receiving treatment with non-anti-TNF biologics prior to study enrollment, 9.7\% $(n=95)$ were treated with rituximab and $4.6 \%(n=45)$ with tocilizumab.

The mean number of biologic treatment failures for second-line patients prior to initiating abatacept was 1.8. Among the 974 patients for whom reasons for 
Table 1 Baseline demographics, disease and clinical characteristics by line-of-treatment category

\begin{tabular}{|c|c|c|c|c|}
\hline Demographic characteristics & $\mathbf{N}$ & First-line $n=118$ & Second-line $n=996$ & Overall $n=1114$ \\
\hline Age, mean (SD) & 1113 & $59.1(13.7)$ & $56.2(12.4)$ & $56.5(12.6)$ \\
\hline Female, n (\%) & 1114 & $82(69.5)$ & $822(82.5)$ & $904(81.1)$ \\
\hline Weight, mean (SD) & 1102 & $75.5(15.9)$ & $74.5(17.0)$ & $74.6(16.9)$ \\
\hline \multicolumn{5}{|l|}{ Disease characteristics } \\
\hline Mean disease duration, years (SD) & 1079 & $6.9(7.7)$ & $11.5(8.9)$ & $11.0(8.9)$ \\
\hline \multicolumn{5}{|l|}{ Disease duration, n (\%) } \\
\hline$\leq 2$ years & & $41(35.3)$ & $100(10.4)$ & $141(13.1)$ \\
\hline $3-5$ years & & $30(25.9)$ & $200(20.8)$ & $230(21.3)$ \\
\hline $6-10$ years & & $21(18.1)$ & $242(25.1)$ & $263(24.4)$ \\
\hline$>10$ years & & $24(20.7)$ & $421(43.7)$ & $445(41.2)$ \\
\hline \multicolumn{5}{|l|}{ Previous treatments } \\
\hline Previously treated with biologic agents, n (\%) & 1114 & $0(0.0)$ & $996(100)$ & $996(89.4)$ \\
\hline At least one anti-TNF agent, $\mathrm{n}(\%)$ & & $0(0.0)$ & $978(98.2)$ & $978(87.8)$ \\
\hline Anti-TNF only & & $0(0.0)$ & $790(79.3)$ & $790(70.9)$ \\
\hline Anti-TNF and another biologic & & $0(0.0)$ & $188(18.9)$ & $188(16.9)$ \\
\hline Other mechanisms of action only & & $0(0.0)$ & $18(1.8)$ & $18(1.6)$ \\
\hline Number of prior anti-TNF agents, mean (SD) & & $0(0.0)$ & $1.6(0.7)$ & $1.4(0.8)$ \\
\hline One, n (\%) & & $0(0.0)$ & $480(48.2)$ & $480(43.1)$ \\
\hline Two, n (\%) & & $0(0.0)$ & $405(40.7)$ & $405(36.4)$ \\
\hline Three, n (\%) & & $0(0.0)$ & $93(9.3)$ & $93(8.3)$ \\
\hline Clinical characteristics & $\mathbf{N}^{*}$ & First-line $\mathrm{N}=111$ & Second-line $N=968$ & Overall $\mathrm{N}=1079$ \\
\hline Tender joint count (28), mean (SD) & 1052 & $11.5(7.3)$ & $11.4(7.3)$ & $11.4(7.3)$ \\
\hline Swollen joint count (28), mean (SD) & 1069 & $9.5(5.8)$ & $7.8(5.8)$ & $8.0(5.9)$ \\
\hline Patient global assessment, mean (SD) (VAS $100 \mathrm{~mm}$ ) & 1002 & $61.9(22.1)$ & $66.2(20.1)$ & $65.8(20.3)$ \\
\hline Physician global assessment, mean (SD) (VAS 100 mm) & 937 & $61.9(18.7)$ & $61.8(19.4)$ & $61.8(19.3)$ \\
\hline Patient global assessment of pain, mean (SD) (VAS $100 \mathrm{~mm}$ ) & 990 & $59.9(24.5)$ & $65.9(20.7)$ & $65.3(21.1)$ \\
\hline Patients with erosions, n (\%) & 926 & $58(58.0)$ & $590(71.4)$ & $648(70.0)$ \\
\hline DAS28 (ESR), mean (SD) & 748 & $5.5(1.3)$ & $5.6(1.2)$ & $5.6(1.2)$ \\
\hline DAS28 (CRP), mean (SD) & 216 & $4.8(1.1)$ & $5.2(1.3)$ & $5.2(1.3)$ \\
\hline $\mathrm{CDAl}$, mean $(\mathrm{SD})$ & 919 & $33.4(13.1)$ & $31.5(13.0)$ & $31.7(13.0)$ \\
\hline SDAl, mean (SD) & 824 & $35.4(13.8)$ & 33.9 (13.8) & $34.0(13.8)$ \\
\hline HAQ-DI, mean (SD) & 988 & $1.42(0.59)$ & $1.56(0.67)$ & $1.55(0.67)$ \\
\hline CRP mg/L, mean (SD) & 943 & $19.6(32.5)$ & $24.4(40.6)$ & $23.9(39.9)$ \\
\hline ESR mm/hour, mean (SD) & 988 & $32.5(23.6)$ & $35.5(24.5)$ & $35.2(24.4)$ \\
\hline Rheumatoid factor positive, $\mathrm{n}(\%)$ & 886 & $64(68.1)$ & $549(69.3)$ & $613(69.2)$ \\
\hline Anti-CCP positive, $\mathrm{n}(\%)$ & 598 & $36(59.0)$ & 354 (65.9) & $390(65.2)$ \\
\hline
\end{tabular}

${ }^{*}$ All patients with relevant baseline data assessed no later than 8 days after the first infusion of abatacept.

CCP, anti-cyclic citrullinated protein; CDAl, Clinical Disease Activity Index; CRP, C-reactive protein; DAS28, Disease Activity Score 28; ESR, erythrocyte sedimentation rate; HAQ-DI, Health Assessment Questionnaire-Disability Index; SD, standard deviation; SDAI, Simplified Disease Activity Index; TNF, tumor necrosis factor; VAS, visual analog scale.

discontinuation of the prior biologic before study enrollment were available, the reasons were: primary inefficacy $(26.6 \%, n=259)$, loss of efficacy (secondary inefficacy) $(46.5 \%, \mathrm{n}=453)$, safety and tolerability $(22.0 \%, \mathrm{n}=214)$, other unspecified reasons $(5.6 \%, \mathrm{n}=55)$, and achieving remission or experiencing a major improvement
$(0.5 \%, \mathrm{n}=5)$. Patients could report more than one reason for discontinuation of prior treatment before study enrollment.

In the first-line treatment group ( $\mathrm{n}=118), 7.6 \%(\mathrm{n}=9)$ of patients initiated abatacept as monotherapy and 92.4\% $(\mathrm{n}=109)$ received it in combination with another 
DMARD, which was MTX in $42.2 \%$ of patients $(n=46)$. Abatacept was initiated in combination with corticosteroids in $64.4 \%(n=76)$ of first-line patients. Of the 996 patients who had previously failed at least one biologic agent, $22.8 \%(n=227)$ received abatacept as monotherapy and $77.2 \%(n=769)$ received abatacept in combination with another DMARD, of whom 61.0\% $(n=469)$ received abatacept in combination with MTX. Abatacept was initiated in combination with corticosteroids in $74.9 \%$ ( $\mathrm{n}=$ 746) of patients in the second-line treatment group.

Patient clinical characteristics by line-of-treatment group are summarized in Table 1 . The majority of patients were at high risk of disease progression: $58.0 \%$ in the first-line group and $71.4 \%$ in the second-line group had erosions, $59.0 \%$ of first-line and $65.9 \%$ of second-line patients were anti-cyclic citrullinated protein positive, and $68.1 \%$ in the first-line and $69.3 \%$ in the second-line group were rheumatoid factor (RF) positive. Overall, patients in both treatment groups had high levels of disease severity at baseline according to DAS28 (ESR), CDAI, and HAQDI scores (Table 1).

Similar proportions of patients from both groups presented with at least one comorbidity at enrollment; most commonly metabolic disorders $(26.8 \%, \mathrm{n}=298)$, including lipid metabolism and deposit disorders (not elsewhere classified [15.9\%, $\mathrm{n}=177])$, and diabetes $(12.1 \%, \mathrm{n}=135)$; endocrine disorders $(14.2 \%, \mathrm{n}=158)$, including hypothyroidism $(10.1 \%, \mathrm{n}=112)$; respiratory disease $(10.1 \%, \mathrm{n}=113)$; and cardiac disorders $(6.4 \%, \mathrm{n}=71)$. Infections and infestations were reported by $5.9 \%(n=66)$ of patients, including $1.4 \%$ $(\mathrm{n}=16)$ of patients with tuberculosis. Other comorbidities at baseline included hepatobiliary disorders $(2.3 \%, \mathrm{n}=26)$, renal disorders $(2.4 \%, \mathrm{n}=27)$, and neoplasms (benign, malignant, and unspecified; $2.6 \%, \mathrm{n}=29$ ).

\section{Retention rate}

Retention rates in abatacept-treated patients are shown in Figure 2. The Kaplan-Meier estimated retention rate at endpoint (Day 169/Month 6) for all evaluable patients $(\mathrm{n}=1114)$ treated with abatacept was $88.6 \%$ (95\% CI: $86.4,90.4)$. For those in the first-line group, the retention rate was $93.0 \%$ (95\% CI: 85.9, 96.6), whereas for patients in the second-line group it was $88.1 \%$ (95\% CI: 85.7, 90.0) (Figure 2A).

For patients in the second-line group, the Kaplan-Meier estimated retention rate at endpoint (Day 169/Month 6) for patients initiating abatacept treatment after $>1$ prior failed anti-TNF treatment was 89.2\% (95\% CI: 85.8, 91.8) and for those who had failed $\geq 2$ anti-TNF therapies it was 86.7\% (95\% CI: 83.1, 89.5). The Kaplan-Meier estimated retention rates based on reasons for discontinuing prior biologic therapy before initiating abatacept were $84.4 \%$ (95\% CI: $79.0,88.6)$ for patients who discontinued due to primary inefficacy, $90.3 \%$ (95\% CI: 86.9, 92.8) for those

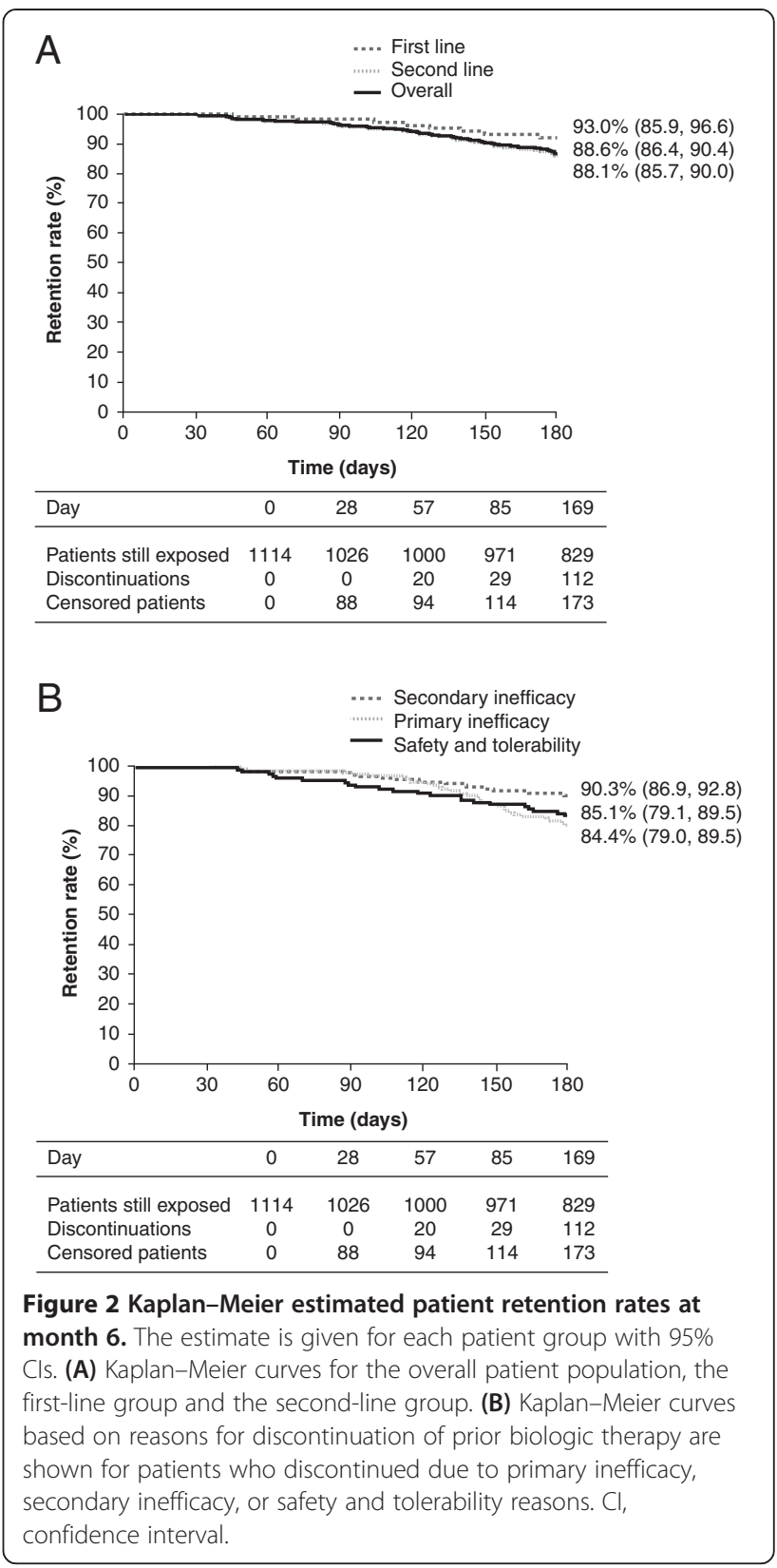

who discontinued due to secondary inefficacy, and $85.1 \%$ (95\% CI: 79.1, 89.5) for those with safety and tolerability issues with anti-TNF agents (Figure 2B). The estimated retention rate was $87.7 \%$ (95\% CI: $82.4,91.5)$ for patients in the second-line group who had received abatacept monotherapy and $88.1 \%$ (95\% CI: 85.4, 90.4) for patients who had received abatacept in combination with a DMARD at initiation.

\section{Effectiveness over 6 months}

Changes in disease state were assessed using the DAS28 (ESR), DAS28 (CRP), and CDAI scores for patients in the overall population with data evaluable for effectiveness at 
baseline and Month 6. Mean (SD) baseline DAS28 (ESR), DAS28 (CRP), and CDAI scores were 5.5 (1.2), 5.2 (1.3), and 31.7 (13.2), respectively, and mean (95\% CI) changes from baseline at Month 6 were $-1.5(-1.6,-1.3),-1.5$ $(-1.7,-1.2)$, and $-15.2(-16.3,-14.1)$, respectively (Table 2$)$. Patients receiving abatacept earlier in the course of treatment (ie, first-line) achieved numerically greater mean changes from baseline in DAS28 (ESR), DAS28 (CRP), and CDAI compared with second-line abatacept, although 95\% CI overlapped (Table 2). Among second-line patients, mean changes from baseline in DAS28 (ESR), DAS28 (CRP), and CDAI were numerically greater among those who failed one prior anti-TNF and those who failed $\geq 2$, but with overlapping 95\% CI (Table 2).

The proportions of patients achieving LDAS or remission are shown in Figure $3 \mathrm{~A}-\mathrm{C}$. The proportions achieving LDAS or remission were higher by the DAS-CRP criteria. By all criteria, a numerically higher proportion of first-line patients achieved both LDAS and remission compared with second-line patients. Among second-line patients, a numerically higher proportion of patients who failed one prior anti-TNF had achieved LDAS and remission, for all three composite scales, compared with patients who had failed $\geq 2$ prior anti-TNFs although 95\% CIs overlapped (Table 3 ).
The proportion of patients achieving a EULAR response is shown in Figure 4. More than $67 \%$ of patients achieved a good or moderate EULAR response, as defined by DAS28 (ESR) or DAS28 (CRP) independently of whether abatacept was initiated as first- or second-line therapy (Figure 4). A good or moderate EULAR response was achieved by similar proportions of patients regardless of whether they had previously failed 1 or $\geq 2$ anti-TNFs (69.2 and 64.5\%, respectively).

Effectiveness was also stratified by reason for discontinuation of patients with prior biologic therapy. Mean change from baseline in DAS28 (ESR), DAS28 (CRP), and CDAI was similar in patients who discontinued their prior biologic due to primary inefficacy, secondary inefficacy, or safety and tolerability issues (Table 4). Slightly different results were observed when considering LDAS and remission (Table 4).

A good or moderate EULAR response was achieved by similar proportions of patients regardless of the reasons for which the last biologic therapy was discontinued (67.2, 66.2, and $67.3 \%$ for those patients who discontinued due to primary inefficacy, secondary inefficacy, or intolerance, respectively). When comparing abatacept as monotherapy versus in combination with a DMARD in

Table 2 Analysis of abatacept effectiveness overall, and stratified by line of therapy, and by number of previous failed anti-TNFs

\begin{tabular}{|c|c|c|c|c|}
\hline \multirow[t]{2}{*}{ Measure } & \multicolumn{2}{|c|}{ Baseline } & \multicolumn{2}{|c|}{ Change from baseline to month 6} \\
\hline & $\mathbf{N}$ & Mean (SD) & & Mean $(95 \% \mathrm{Cl})$ \\
\hline & & Overall & & \\
\hline DAS28 (ESR) & 539 & $5.5(1.2)$ & 473 & $-1.5(-1.6,-1.3)$ \\
\hline DAS28 (CRP) & 151 & $5.2(1.3)$ & 113 & $-1.5(-1.7,-1.2)$ \\
\hline \multirow[t]{2}{*}{ CDAI } & 647 & $31.7(13.2)$ & 605 & $-15.2(-16.3,-14.1)$ \\
\hline & & First-line & & \\
\hline DAS28 (ESR) & 33 & $5.2(1.2)$ & 29 & $-1.7(-2.3,-1.1)$ \\
\hline DAS28 (CRP) & 5 & $4.5(1.3)$ & 4 & $-2.0(-3.2,-0.8)$ \\
\hline \multirow[t]{2}{*}{ CDAI } & 48 & $31.9(11.9)$ & 41 & $-18.3(-22.0,-14.6)$ \\
\hline & & Second-line & & \\
\hline DAS28 (ESR) & 506 & $5.6(1.2)$ & 444 & $-1.5(-1.6,-1.3)$ \\
\hline DAS28 (CRP) & 146 & $5.3(1.3)$ & 109 & $-1.4(-1.7,-1.2)$ \\
\hline \multirow[t]{2}{*}{ CDAI } & 599 & $31.7(13.2)$ & 564 & $-15.0(-16.1,-13.9)$ \\
\hline & & previous ant & & \\
\hline DAS28 (ESR) & 247 & $5.5(1.2)$ & 221 & $-1.6(-1.8,-1.4)$ \\
\hline DAS28 (CRP) & 64 & $5.2(1.3)$ & 46 & $-1.7(-2.2,-1.2)$ \\
\hline \multirow[t]{2}{*}{ CDAI } & 291 & $30.6(12.7)$ & 278 & $-15.0(-16.5,-13.5)$ \\
\hline & & revious anti- & & \\
\hline DAS28 (ESR) & 251 & $5.6(1.3)$ & 216 & $-1.3(-1.5,-1.1)$ \\
\hline DAS28 (CRP) & 78 & $5.3(1.4)$ & 59 & $-1.2(-1.6,-0.8)$ \\
\hline CDAI & 295 & 32.5 (13.6) & 275 & $-14.7(-16.4,-12.9)$ \\
\hline
\end{tabular}

CDAl, Clinical Disease Activity Index; Cl, confidence interval; CRP, C-reactive protein; DAS28, Disease Activity Score 28; ESR, erythrocyte sedimentation rate; LDAS, low disease activity state; SD, standard deviation; TNF, tumor necrosis factor. 


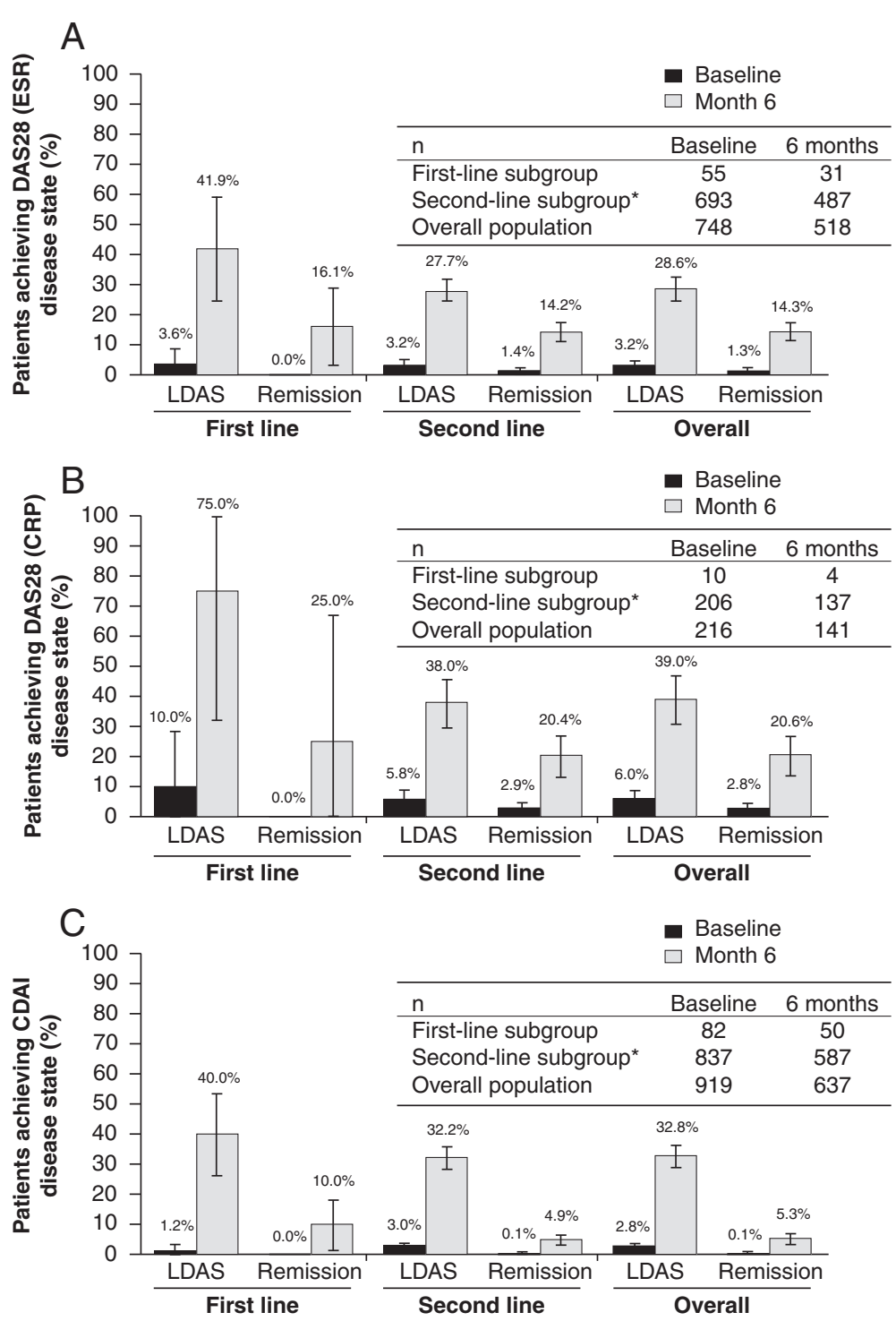

Figure 3 Proportion of patients with LDAS or remission at baseline and at month 6. (A) Assessed by the DAS28 (ESR), (B) by the DAS28 (CRP), and (C) by the CDAI. LDAS was defined as a DAS28 score $\leq 3.2$ or a CDAl score $\leq 10$. Remission was defined as a DAS28 score $<2.6$ or a CDAl score $\leq 2.8$. Error bars represent $95 \% \mathrm{Cl}$. *Includes patients receiving abatacept as a second- or further-line of treatment. CDAl, Clinical Disease Activity Index; Cl, confidence interval; CRP, C-reactive protein; DAS28, 28-item Disease Activity Score; ESR, erythrocyte sedimentation rate; LDAS, low disease activity state.

patients treated with abatacept as second-line or higher, $63.1 \%(n=65 / 103)$ versus $68.3 \%(n=254 / 372)$ of patients achieved a good or moderate EULAR response, 27.5\% ( $\mathrm{n}=38 / 138)$ versus $33.6 \%(\mathrm{n}=151 / 449)$ achieved CDAI LDAS, and $5.1 \%(\mathrm{n}=7 / 138)$ versus $4.9 \%(\mathrm{n}=22 /$ 449) achieved CDAI remission.

Among patients for whom data were available at Month 6, the mean (SD) baseline HAQ-DI was 1.5 (0.6), and the mean change in HAQ-DI score from baseline to Month 6 was -0.30 (95\% CI: $-0.35,-0.26)$. After 6 months of abatacept treatment, $44.7 \%$ achieved a HAQ response ( $\geq 0.3$ unit change from baseline), and $55.0 \%$ of patients achieved a clinically meaningful change $(\geq 0.22$ unit change from baseline). Patients receiving abatacept earlier in the course of treatment (ie, first-line) achieved numerically greater mean changes from baseline in HAQDI compared with second-line abatacept $(-0.44$, [95\% CI: $-0.58,-0.29$ ] versus -0.29 [ $95 \% \mathrm{CI}:-0.34,-0.24]$, respectively), although 95\% CIs overlapped. A greater proportion of first-line patients achieved a HAQ-DI response compared with second-line patients (60.3\% [95\% CI: 47.8, 72.9] versus 43.1\% [95\% CI: 39.0, 47.2], respectively). Among second-line patients, the mean change from baseline in HAQ-DI $(-0.35$ [95\% CI: $-0.42,-0.28$ ] versus -0.23 
Table 3 Proportion of patients with LDAS* or remission at baseline and at Month 6 for second line abatacept stratified by 1 or $\geq 2$ prior anti-TNF agent

\begin{tabular}{|c|c|c|c|c|}
\hline \multirow[t]{2}{*}{ Measure } & \multicolumn{2}{|c|}{ Remission at month 6} & \multicolumn{2}{|c|}{ LDAS* at month 6} \\
\hline & $\mathrm{N}$ & Percent $(95 \% \mathrm{Cl})$ & $\mathrm{N}$ & Percent $(95 \% \mathrm{Cl})$ \\
\hline \multicolumn{5}{|c|}{ One previous anti-TNF } \\
\hline DAS28 (ESR) & 245 & $15.9(11.3,20.5)$ & 245 & $29.8(24.1,35.5)$ \\
\hline DAS28 (CRP) & 57 & $22.8(11.9,33.7)$ & 57 & $42.1(29.3,54.9)$ \\
\hline CDAI & 289 & $5.2(2.6,7.7)$ & 289 & $35.6(30.1,41.2)$ \\
\hline \multicolumn{5}{|c|}{$\geq 2$ previous anti-TNFs } \\
\hline DAS28 (ESR) & 234 & $12.8(8.5,17.1)$ & 234 & $25.6(20.0,31.2)$ \\
\hline DAS28 (CRP) & 75 & $17.3(8.8,25.9)$ & 75 & $33.3(22.7,44.0)$ \\
\hline CDAI & 286 & $4.9(2.4,7.4)$ & 286 & $28.3(23.1,33.5)$ \\
\hline
\end{tabular}

*LDAS includes patients in remission (DAS remission: <2.6; CDAl remission: $\leq 2.8$ ).

CDAl, Clinical Disease Activity Index; DAS, Disease Activity Score; LDAS, Low Disease Activity Score ( $\leq 3.2$ for DAS and $\leq 10$ for CDAl)

[95\% CI: $-0.29,-0.17])$ and the proportion of patients achieving a HAQ-DI response (48.5 [95\% CI: 42.6, 54.5] versus 37.1\% [95\% CI: 31.4, 42.8]) were greater among those who failed one prior anti-TNF compared to those who failed $\geq 2$.

\section{Concomitant medication}

Overall, 822/1114 (73.8\%) and 555/770 (72.1\%) of patients were receiving concomitant corticosteroids at abatacept initiation and at 6 months, respectively. The median dose decreased from $7.5 \mathrm{mg} /$ day $(\mathrm{n}=724)$ to $5 \mathrm{mg} /$ day $(\mathrm{n}=494)$ over 6 months. Among those who were on concomitant corticosteroids at abatacept initiation and for whom 6-month data were available, 39/555 (7.0\%) of patients discontinued all corticosteroids from initiation to 6 months, and 141/462 (30.5\%) patients had

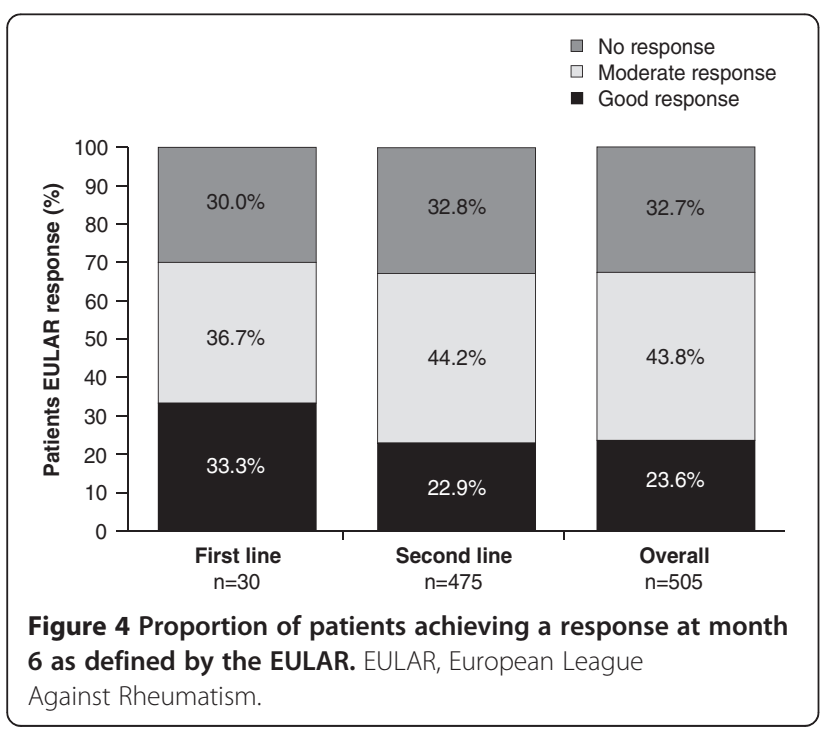

a dose decrease from $10 \mathrm{mg} /$ day (median dose at initiation) to $5 \mathrm{mg} /$ day (median dose at 6 months). Among patients who were not on concomitant corticosteroids at abatacept initiation and for whom 6-month data were available, 39/215 (18.1\%) of patients had concomitant corticosteroids introduced to their treatment regimen between abatacept initiation and Month 6; the median dose at Month 6 was $7.5 \mathrm{mg} /$ day. From initiation to Month 6, 30/770 (3.9\%) patients discontinued all concomitant DMARDs, whereas 20/770 (2.6\%) patients had concomitant DMARDs introduced during the first 6 months after abatacept initiation.

\section{Safety}

Safety was reported for all 1138 enrolled patients, and no new or unexpected AEs were reported. SAEs were reported in $4.7 \%(n=54 / 1138)$ of patients and discontinuations due to SAEs occurred in $1.8 \%(n=20 / 1138)$ of patients. Nine deaths were reported throughout the study. Causes of death $(\mathrm{n}=1$, each) were: aspiration pneumonia secondary to withdrawal from benzodiazepines, asthma and stroke, seizure, heart attack, urosepsis, suicide, Pneumocystis jiroveci pulmonary infection, sepsis, and unknown.

Serious infections were reported in $1.7 \%(\mathrm{n}=19)$ of patients. No cases of active tuberculosis were reported and one case of opportunistic infection (Pneumocystis jiroveci) was reported but not confirmed by culture. Investigators considered these infections to be unrelated to treatment. Nine patients presented with malignancies during the study that were not considered related to treatment. Five patients had serious cardiac disorders and three had vascular disorders (stroke, transient ischemic event, and deep-vein thrombosis). Diverticular perforation resulting in sepsis was reported in one patient, for which surgery was performed. One severe acute systemic infusion reaction as the result of an allergic reaction was reported 25 minutes after beginning an abatacept infusion. Pulmonary disorders were reported in seven patients during the study, including one patient with an event of bronchitis, who had known pre-existing risk factors (tobacco use and grade II chronic obstructive pulmonary disease).

\section{Discussion}

ACTION was the first international, non-interventional, multicenter, prospective cohort study to evaluate patient retention and effectiveness of abatacept treatment in patients with moderate-to-severe RA. The current interim analysis evaluated a 6-month dataset from this ongoing 2-year study. This 6-month interim analysis may be particularly pertinent to clinicians because, according to the treat-to-target approach, the decision to switch a biologic therapy is usually made 3-6 months after initiating 
Table 4 Subgroup analysis of second-line abatacept effectiveness by reasons for treatment failure

\begin{tabular}{|c|c|c|c|c|c|c|c|c|}
\hline \multirow[t]{2}{*}{ Measure } & \multicolumn{2}{|c|}{ Baseline } & \multicolumn{2}{|c|}{ Change from baseline to month 6} & \multicolumn{2}{|c|}{ Remission at month 6} & \multicolumn{2}{|c|}{ LDAS at month 6} \\
\hline & $\mathbf{N}$ & Mean (SD) & $\mathbf{N}$ & Mean $(95 \% \mathrm{Cl})$ & $\mathbf{N}$ & Percent $(95 \% \mathrm{Cl})$ & $\mathbf{N}$ & Percent $(95 \% \mathrm{Cl})$ \\
\hline \multicolumn{9}{|c|}{ Primary inefficacy } \\
\hline DAS28 (ESR) & 129 & $5.6(1.3)$ & 113 & $-1.5(-1.7,-1.2)$ & 119 & $17.6(10.8,24.5)$ & 119 & $29.4(21.2,37.6)$ \\
\hline DAS28 (CRP) & 35 & $5.2(1.3)$ & 26 & $-1.3(-2.0,-0.7)$ & 32 & $12.5(1.0,24.0)$ & 32 & $34.4(17.9,50.8)$ \\
\hline CDAI & 140 & $32.1(13.1)$ & 129 & $-13.9(-16.3,-11.5)$ & 136 & $2.9(0.1,5.8)$ & 136 & $27.9(20.4,35.5)$ \\
\hline \multicolumn{9}{|c|}{ Secondary inefficacy } \\
\hline DAS28 (ESR) & 249 & $5.6(1.1)$ & 219 & $-1.4(-1.6,-1.2)$ & 240 & $10.4(6.6,14.3)$ & 240 & $25.0(19.5,30.5)$ \\
\hline DAS28 (CRP) & 74 & $5.5(1.3)$ & 55 & $-1.6(-2.0,-1.3)$ & 68 & $20.6(11.0,30.2)$ & 68 & $38.2(26.7,49.8)$ \\
\hline CDAI & 295 & $32.5(13.0)$ & 279 & $-15.4(-17.1,-13.8)$ & 288 & $4.2(1.9,6.5)$ & 288 & $29.5(24.2,34.8)$ \\
\hline \multicolumn{9}{|c|}{ Safety and tolerability } \\
\hline DAS28 (ESR) & 91 & $5.5(1.3)$ & 84 & $-1.5(-1.8,-1.2)$ & 98 & $18.4(10.7,26.0)$ & 98 & $29.6(20.6,38.6)$ \\
\hline DAS28 (CRP) & 27 & $4.8(1.4)$ & 22 & $-1.5(-2.2,-0.9)$ & 26 & $30.8(13.0,48.5)$ & 26 & $42.3(23.3,61.3)$ \\
\hline CDAI & 121 & 30.4 (13.4) & 115 & $-15.2(-17.6,-12.8)$ & 119 & $8.4(3.4,13.4)$ & 119 & $38.7(29.9,47.4)$ \\
\hline
\end{tabular}

CDAl, Clinical Disease Activity Index; CRP, C-reactive protein; DAS, Disease Activity Score; ESR, erythrocyte sedimentation rate.

treatment. Here, we demonstrate high patient retention on abatacept, efficacy benefits with regards to disease activity and physical function, and a safety profile consistent with observations from both RCTs and local national registries. Benefits were observed in biologic-naïve and anti-TNF-refractory patients, regardless of the number of previously failed anti-TNF agents, or whether failure was due to primary or secondary inefficacy, or safety and tolerability reasons. In the current study, approximately $70 \%$ of enrolled patients were RF positive, which is consistent with the proportion of RF-positive patients enrolled in abatacept RCTs (ATTAIN study, 73.3\%; ARRIVE, $61.3 \%)[13,32]$ and in real-life abatacept studies (ORA, 72.5\%) [33].

It has been reported that treatment response rates are often lower in routine clinical practice compared with RCT evidence [7], as a result of the patient populations in observational studies not being subject to the strict inclusion and exclusion criteria of RCTs. However, the heterogeneity of patient populations and disease characteristics in observational studies provide a real-world perspective of routine clinical practice. The efficacy, safety, and tolerability of abatacept for the treatment of moderate-to-severe RA have been demonstrated in RCTs [10-14], in local national registries [15,16], and in a small, single-site observational study [18]. Therefore, the objective of the ACTION study was to translate the validity of RCT results into a real-life setting. Given the objective of the study, a single-arm design was considered appropriate to describe a cohort of patients treated with abatacept and assess their drug utilization in accordance with the European Medicines Agency and Health Technology Assessment Programmes' recommendations.

Retention rates reported in the current trial were high $->80.0 \%$ for second-line and $93.0 \%$ for first-line patients - compared with evidence from other realworld observational studies. Evidence from the Swedish national registry ARTIS showed that, 1 year after initiating abatacept treatment, retention rates were $80 \%$ for biologic-naïve patients and $64 \%$ for patients previously treated with 1-2 biologics [17]. Similarly, 6-month retention rates with abatacept treatment were $72.0 \%$ in the Danish DANBIO registry [16] and $80.0 \%$ in a US observational study [18]. Although retention rates for RCTs are expected to be higher than for real-world studies [7], the retention rates in the current study were consistent with an $82-90 \%$ retention rate reported from two abatacept RCTs, the ATTAIN and ARRIVE studies [13,32]. Of note was the high retention rate for biologic-naïve patients in the current study (93.0\%), which is consistent with evidence from abatacept RCTs showing that patient retention is higher when abatacept is initiated earlier in the treatment regimen $[11,14]$.

The efficacy of abatacept in the current report was assessed using multiple disease activity measures (DAS28, CDAI, and EULAR response); each of the clinical indices showed the same trend for improved effectiveness with abatacept, including the CDAI. Changes in disease activity in the current study were consistent with those reported in the DANBIO national registry [16] and the French ORA registry [33]. A good-to-moderate treatment response, as defined by EULAR, was achieved by more than $67 \%$ of both first- and second-line patients in the current analysis; this was consistent with 6-month evidence from the French ORA national registry [33] and the Danish DANBIO registry [16]. In addition, response and remission rates with abatacept in the ACTION study were similar to those reported in the two previously mentioned abatacept RCTs in patients with a prior inadequate response to anti-TNF agents, the ATTAIN [13] and ARRIVE 
studies [32]. Subgroup analysis from ACTION - according to the number of prior anti-TNFs failed or according to the reason for discontinuation of the last biologic prior to abatacept - highlight that abatacept has favorable safety and tolerability in a real-world setting, regardless of the number of prior anti-TNFs failed or the reason for failure. These data support previously reported favorable outcomes from the ARRIVE [32] trial in patients with similar characteristics. Furthermore, the subgroup analyses in ACTION showed consistent numerically superior outcomes for patients treated with abatacept earlier in their disease course. As the study was not powered for subgroups analysis, definitive conclusions cannot be drawn.

Overall, no new safety signals were identified in the ACTION patient population compared with the safety profile previously reported for abatacept from real-world studies $[16,18]$. Of note is the absence of any cases of active tuberculosis and one report of opportunistic infection. It is important to note that a large number of patients enrolled in the ACTION study had cardiovascular and pulmonary comorbidities, as well as chronic infections, at baseline, reflecting the type of patient profile often found in routine clinical practice compared with RCTs.

Although the results of some observational studies indicate that, after the failure of 1 or $\geq 2$ anti-TNF agents, the choice of a biological agent with a different mechanism of action may lead to better clinical outcomes, there are a number of limitations associated with such analyses [34]. To our knowledge, there is little evidence from real-life settings that directly compares abatacept with another biologic agent or biologic agents with each other. When interpreting the results of the current study, there are a number of potential limitations to be considered including lack of an active comparator and/ or selection bias based on factors such as disease severity or AEs. In addition, failure of multiple biologics prior to abatacept treatment may have influenced physicians to wait longer before deciding that a treatment was ineffective, potentially affecting the retention rate by Month 6. This interim analysis was also vulnerable to missing data as none of the study assessments were mandatory; thus, most missing clinical outcome data may have been attributed to assessments not performed routinely at all locations. Consequently, of the $24.7 \%$ of patients with missing numerical DAS28 scores, $15.9 \%$ were reported by the investigators as score 'not calculated'. Here, we report data 'as observed' with no imputation for missing values, which is consistent with other non-interventional studies.

\section{Conclusions}

This large, observational, real-world study demonstrated high patient retention rates with abatacept treatment, regardless of line of treatment (first or second), the number of previously failed anti-TNF agents, or the reason for treatment failure. In addition, the data suggest that patients treated earlier in their disease course with abatacept have better outcomes than patients treated after failure of one or more anti-TNF agents. Rates of retention, LDAS, remission, HAQ-DI response, and safety outcomes were consistent with data from both abatacept RCTs and local national registries. Furthermore, increased proportions of patients achieved remission or LDAS after 6 months of abatacept treatment following the failure of $<2$ anti-TNF agents, compared with those who had failed $\geq 2$ anti-TNF agents. The findings presented here underline that abatacept, when used alone or in combination with DMARDs, provides a welltolerated and effective treatment option for patients with RA, including those for whom previous anti-TNF treatment has failed. These data further support the use of abatacept monotherapy in clinical practice, as reflected by observations from RA registries [6,33]. Future analyses of the ACTION study will evaluate the long-term effectiveness, retention rates, and safety of abatacept in the real-world setting.

\section{Abbreviations}

ACTION: AbataCepT In rOutiNe clinical practice; AE: Adverse event; CDAl: Clinical disease activity index; Cl: Confidence interval; CRP: C-reactive protein; DAS28: 28-item disease activity score; DMARD: Disease-modifying anti-rheumatic drug; ESR: Erythrocyte sedimentation rate; EULAR: European league against rheumatism; HAQ-DI: Health assessment questionnairedisability index; LDAS: Low disease activity state; MTX: Methotrexate; RA: Rheumatoid arthritis; RCT: Randomized clinical trials; RF: Rheumatoid factor; SAE: Serious adverse event; SD: Standard deviation; TNF: Tumor necrosis factor.

\section{Competing interests}

H.G. Nüßlein has received consulting fees and speaker honoraria from BristolMyers Squibb, Abbott, Chugai, UCB, Essex, Wyeth, Pfizer, MSD, Novartis, and Roche. R. Alten has received research grants from Bristol-Myers Squibb, Merck Pharma GmbH, Novartis, UCB, Roche, and Pfizer; speaker honoraria from Abbott Laboratories, Bristol-Myers Squibb, Horizon Pharma, Novartis, and Roche; and consulting fees from Abbott Laboratories, Horizon Pharma, Novartis, and Roche. M. Galeazzi has nothing to disclose. H.-M. Lorenz has received honoraria from Bristol-Myers Squibb for presentations and participation in advisory boards, and provides advice on planning of the ACTION study. D. Boumpas has nothing to disclose. M.T. Nurmohamed has received consultancy fees from Abbott, Roche, Pfizer, MSD, UCB, SOBI, and Bristol-Myers Squibb, and has received payment for lectures from Abbott, Roche, Bristol-Myers Squibb, and Pfizer. W.G. Bensen has attended advisory boards, presented data, and performed research for Bristol-Myers Squibb, Amgen, Abbott, UCB, Merck, Pfizer, Novartis, AstraZeneca, Roche, Janssen, Warner Chilcott, and Sanofi-Aventis. G.R. Burmester has received consulting fees from Abbott Immunology Pharmaceuticals, BMS, Roche, Merck, and Pfizer; research grants from Abbott Laboratories, Abbott Immunology Pharmaceuticals, Bristol-Myers Squibb, and Roche; and speaker honoraria from Abbott Immunology Pharmaceuticals, Bristol-Myers Squibb, and Roche. H.-H. Peter has nothing to disclose. F. Rainer has nothing to disclose. K. Pavelka has been a speaker for Pfizer, Amgen, MSD, Bristol-Myers Squibb, and Abbott. M. Chartier is a consultant for Bristol-Myers Squibb. C. Poncet is a consultant for Bristol-Myers Squibb. C. Rauch is an employee of Bristol-Myers Squibb. M. Le Bars is an employee of Bristol-Myers Squibb and holds stock options.

\section{Authors' contributions}

HGN made a substantial contribution to the conception and design of the study, to the acquisition of data, and to the analysis and interpretation 
of data. RA made a substantial contribution to the conception and design of the study, and to the analysis and interpretation of data. MG made a substantial contribution to the acquisition of data, and to the analysis and interpretation of data. HML made a substantial contribution to the conception and design of the study, to the acquisition of data, and to the analysis and interpretation of data. DB made a substantial contribution to the conception and design of the study, to the acquisition of data, and to the analysis and interpretation of data. MTN made a substantial contribution to the acquisition of data. WGB made a substantial contribution to the acquisition of data. GRB made a substantial contribution to the acquisition of data, and to the analysis and interpretation of data. HHP made a substantial contribution to the acquisition of data, and to the analysis and interpretation of data. FR made a substantial contribution to the acquisition of data. KP made a substantial contribution to the acquisition of data. MC made a substantial contribution to the conception and design of the study, to the acquisition of data, and to the analysis and interpretation of data. CP made a substantial contribution to the conception and design of the study, and to the analysis and interpretation of data. CR made a substantial contribution to the conception and design of the study, to the acquisition of data, and to the analysis and interpretation of data. MLB made a substantial contribution to the conception and design of the study, to the acquisition of data, and to the analysis and interpretation of data. All authors have read and approved the final manuscript.

\section{Acknowledgments}

The authors would like to thank all physicians who participated in the ACTION study. The ACTION study was funded by Bristol-Myers Squibb. Gill Litalien (Executive Director, Global Health Economics and Outcomes Research) and Nathalie Schmidely (Associate Director Real World Research) from Bristol-Myers Squibb provided input into the design and interpretation of this study. Clinical research organizations involved in the ACTION study were Inventiv Health Clinical, Winicker Norimed, TFS Trial Form Support S.r.l., and Archemin BVBA, and statistical analyses support was provided by Stat Process. Professional medical writing and editorial assistance was provided by Medicus International and by Mailee Wong, PhD, at Caudex Medical, and was funded by Bristol-Myers Squibb.

\section{Funding}

The ACTION study was funded by Bristol-Myers Squibb. Professional medical writing and editorial assistance was provided by Medicus International (London, UK) and by Mailee Wong, PhD, at Caudex Medical, and funded by Bristol-Myers Squibb.

\section{Author details}

${ }^{1}$ University of Erlangen-Nuremberg, Nuremberg, Germany. ${ }^{2}$ Schlosspark-Klinik, University Medicine, Berlin, Germany. ${ }^{3}$ University of Siena, Siena, Italy. ${ }^{4}$ University Hospital Heidelberg, Heidelberg, Germany. ${ }^{5}$ University of Crete, Heraklion, Greece. ${ }^{6}$ VU University Medical Center/Jan van Breemen Research Institute, Amsterdam, The Netherlands. 'St. Joseph's Hospital/McMaster University, Hamilton, Ontario, Canada. ${ }^{8}$ Charité-Universitätsmedizin Berlin, Berlin, Germany. ${ }^{9}$ University Medical Center Freiburg, Freiburg, Germany. ${ }^{10}$ Hospital Barmherzige Brueder, Graz, Austria. ${ }^{11}$ Institute of Rheumatology and Clinic of Rheumatology, Charles University, Prague, Czech Republic. ${ }^{12}$ Chiltern International, Neuilly, France. ${ }^{13}$ Docs International, Sèvres, France. ${ }^{14}$ Bristol-Myers Squibb, Munich, Germany. ${ }^{15}$ Bristol-Myers Squibb, Rueil-Malmaison, France.

Received: 3 September 2013 Accepted: 2 January 2014 Published: 11 January 2014

\section{References}

1. van Vollenhoven RF: Switching between anti-tumour necrosis factors: trying to get a handle on a complex issue. Ann Rheum Dis 2007, 66:849-851.

2. Du Pan SM, Dehler S, Ciurea A, Ziswiler HR, Gabay C, Finckh A: Comparison of drug retention rates and causes of drug discontinuation between anti-tumor necrosis factor agents in rheumatoid arthritis. Arthritis Rheum 2009, 61:560-568.

3. Hyrich KL, Lunt M, Watson KD, Symmons DP, Silman AJ: Outcomes after switching from one anti-tumor necrosis factor alpha agent to a second anti-tumor necrosis factor alpha agent in patients with rheumatoid arthritis: results from a large UK national cohort study. Arthritis Rheum 2007, 56:13-20.

4. Wolbink GJ, Vis M, Lems W, Voskuyl AE, de Groot E, Nurmohamed MT, Stapel S, Tak PP, Aarden L, Dijkmans B: Development of antiinfliximab antibodies and relationship to clinical response in patients with rheumatoid arthritis. Arthritis Rheum 2006, 54:711-715.

5. Duclos M, Gossec L, Ruyssen-Witrand A, Salliot C, Luc M, Guignard S, Dougados $\mathrm{M}$ : Retention rates of tumor necrosis factor blockers in daily practice in 770 rheumatic patients. J Rheumatol 2006, 33:2433-2438.

6. Du Pan SM, Scherer A, Gabay C, Finckh A: Differential drug retention between anti-TNF agents and alternative biological agents after inadequate response to an anti-TNF agent in rheumatoid arthritis patients. Ann Rheum Dis 2012, 71:997-999.

7. Caporali R, Pallavicini FB, Filippini M, Gorla R, Marchesoni A, Favalli EG, Sarzi-Puttini P, Atzeni F, Montecucco C: Treatment of rheumatoid arthritis with anti-TNFalpha agents: a reappraisal. Autoimmun Rev 2009, 8:274-280.

8. Kievit W, Fransen J, Oerlemans AJ, Kuper HH, van der Laar MA, de Rooij DJ, De Gendt CM, Ronday KH, Jansen TL, van Oijen PC, Brus HL, Adang EM, van Riel PL: The efficacy of anti-TNF in rheumatoid arthritis, a comparison between randomised controlled trials and clinical practice. Ann Rheum Dis 2007, 66:1473-1478.

9. Emery P: Optimizing outcomes in patients with rheumatoid arthritis and an inadequate response to anti-TNF treatment. Rheumatology (Oxford) 2012, 51(Suppl 5):V22-v30.

10. Kremer JM, Genant HK, Moreland LW, Russell AS, Emery P, Abud-Mendoza C, Szechinski J, Li T, Ge Z, Becker JC, Westhovens R: Effects of abatacept in patients with methotrexate-resistant active rheumatoid arthritis: a randomized trial. Ann Intern Med 2006, 144:865-876.

11. Kremer JM, Genant HK, Moreland LW, Russell AS, Emery P, Abud-Mendoza C, Szechiński J, Li T, Teng J, Becker JC, Westhovens R: Results of a two-year followup study of patients with rheumatoid arthritis who received a combination of abatacept and methotrexate. Arthritis Rheum 2008, 58:953-963.

12. Westhovens R, Kremer J, Emery P, Russell A, Li T, Aranda R, Becker JC, Zhao C, Dougados M: Consistent safety and sustained improvement in disease activity and treatment response over 7 years of abatacept treatment in biologic-naïve patients with RA [abstract]. Ann Rheum Dis 2009, 68(3):577. SAT0108.

13. Genovese MC, Becker JC, Schiff M, Luggen M, Sherrer Y, Kremer J, Birbara C, Box J, Natarajan K, Nuamah I, Li T, Aranda R, Hagerty DT, Dougados M: Abatacept for rheumatoid arthritis refractory to tumor necrosis factor alpha inhibition. N Engl J Med 2005, 353:1114-1123.

14. Genovese MC, Schiff M, Luggen M, Becker JC, Aranda R, Teng J, Li T, Schmidely N, Le Bars M, Dougados M: Efficacy and safety of the selective co-stimulation modulator abatacept following 2 years of treatment in patients with rheumatoid arthritis and an inadequate response to anti-tumour necrosis factor therapy. Ann Rheum Dis 2008, 67:547-554.

15. Mariette $X$, Gottenberg JE, Ravaud P, Combe B: Registries in rheumatoid arthritis and autoimmune diseases: data from the French registries. Rheumatology (Oxford) 2011, 50:222-229.

16. Leffers HC, Ostergaard M, Glintborg B, Krogh NS, Foged H, Tarp U, Lorenzen T, Hansen A, Hansen MS, Jacobsen MS, Dreyer L, Hetland ML: Efficacy of abatacept and tocilizumab in patients with rheumatoid arthritis treated in clinical practice: results from the nationwide Danish DANBIO registry. Ann Rheum Dis 2011, 70:1216-1222.

17. Lindblad S, Stawiarz L, Swedish Rheumatology Quality Register: Gender and previous treatment influence outcomes from abatacept in a 5-year rheumatoid arthritis cohort [Abstract]. Ann Rheum Dis 2012, 71(3):383. FRI0205.

18. Schiff M, Poncet C, Bars ML: Efficacy and safety of abatacept therapy for rheumatoid arthritis in routine clinical practice. Int I Clin Rheumatol 2010, 5:581-591.

19. Arnett FC, Edworthy SM, Bloch DA, McShane DJ, Fries JF, Cooper NS, Healey LA, Kaplan SR, Liang MH, Luthra HS, et al: The American Rheumatism Association 1987 revised criteria for the classification of rheumatoid arthritis. Arthritis Rheum 1988, 31:315-324.

20. International Conference on Harmonisation: Good Clinical Practice: Consolidated Guideline; Notice of Availability, 62 Federal Register 90:; 1997:25691-25709.

21. Olsen J: In Good Epidemiological Practice (GEP): IEA Guidelines For Proper Conduct In Epidemiologic Research. Edited by Stewart S, Pearce P, Florey C, Du V. IEA-European Federation; 2007. 
22. D'Agostino M, Wakefield R, Berner Hammer H, Vittecoq O, Galeazzi M, Balint P, Fillipucci E, Moller I, lagnocco A, Naredo E, Ostergaard M, Gaillez C, Kerselaers W, Van Holder K, Le Bars M: Early response to abatacept plus MTX in MTX-IR RA patients using power doppler ultrasonography: an open-label study - poster tours. Ann Rheum Dis 2012, 71(3):186. THU0095.

23. Prevoo ML, van't Hof MA, Kuper HH, van Leeuwen MA, van de Putte LB, van Riel PL: Modified disease activity scores that include twenty-eight-joint counts. Development and validation in a prospective longitudinal study of patients with rheumatoid arthritis. Arthritis Rheum 1995, 38:44-48.

24. Wells G, Becker JC, Teng J, Dougados M, Schiff M, Smolen J, Aletaha D, van Riel PL: Validation of the 28-joint disease activity score (DAS28) and European league against rheumatism response criteria based on C-reactive protein against disease progression in patients with rheumatoid arthritis, and comparison with the DAS28 based on erythrocyte sedimentation rate. Ann Rheum Dis 2009, 68:954-960.

25. Aletaha D, Smolen J: The simplified disease activity index (SDAI) and the clinical disease activity index (CDAl): a review of their usefulness and validity in rheumatoid arthritis. Clin Exp Rheumatol 2005, 23(5 Suppl 39): S100-S108.

26. Dougados M, Aletaha D, van Riel P: Disease activity measures for rheumatoid arthritis. Clin Exp Rheumatol 2007, 25(5 Suppl 46):S22-S29.

27. Fransen J, van Riel PL: The disease activity score and the EULAR response criteria. Clin Exp Rheumatol 2005, 23(5 Suppl 39):S93-S99.

28. Fries JF, Spitz P, Kraines RG, Holman HR: Measurement of patient outcome in arthritis. Arthritis Rheum 1980, 23:137-145.

29. Wells GA, Tugwell P, Kraag GR, Baker PR, Groh J, Redelmeier DA: Minimum important difference between patients with rheumatoid arthritis: the patient's perspective. J Rheumatol 1993, 20:557-560

30. Kosinski M, Zhao SZ, Dedhiya S, Osterhaus JT, Ware JE Jr: Determining minimally important changes in generic and disease-specific healthrelated quality of life questionnaires in clinical trials of rheumatoid arthritis. Arthritis Rheum 2000, 43:1478-1487.

31. Redelmeier DA, Lorig K: Assessing the clinical importance of symptomatic improvements. An illustration in rheumatology. Arch Intern Med 1993, 153:1337-1342

32. Schiff M, Pritchard C, Huffstutter JE, Rodriguez-Valverde V, Durez P, Zhou X, Li T, Bahrt K, Kelly S, Le Bars M, Genovese MC: The 6-month safety and efficacy of abatacept in patients with rheumatoid arthritis who underwent a washout after anti-tumour necrosis factor therapy or were directly switched to abatacept: the ARRIVE trial. Ann Rheum Dis 2009, 68:17081714.

33. Gottenberg JE, Ravaud P, Bardin T, Cantagrel A, Combe B, Dougados M, et al: Prospective follow-Up of RA patients (1200 patient/years) treated with abatacept in real life: results from the ORA registry [abstract]. Ann Rheum Dis 2011, 70(3):466. FRI0364.

34. Smolen JS, Aletaha D: Forget personalised medicine and focus on abating disease activity. Ann Rheum Dis 2013, 72:3-6.

doi:10.1186/1471-2474-15-14

Cite this article as: Nüßlein et al: Real-world effectiveness of abatacept for rheumatoid arthritis treatment in European and Canadian populations: a 6-month interim analysis of the 2-year, observational, prospective ACTION study. BMC Musculoskeletal Disorders 2014 15:14.

\section{Submit your next manuscript to BioMed Central and take full advantage of:}

- Convenient online submission

- Thorough peer review

- No space constraints or color figure charges

- Immediate publication on acceptance

- Inclusion in PubMed, CAS, Scopus and Google Scholar

- Research which is freely available for redistribution

Submit your manuscript at www.biomedcentral.com/submit 